\title{
EXPLOTACIÓN DE CANTERAS EN LA COSTA DE KENITRA Y SU ÁREA DE INFLUENCIA: ESTUDIO DE IMPACTO AMBIENTAL. ${ }^{1}$
}

\section{QUARRYING IN COASTAL KENIKRA AND ITS AREA OF INFLUENCE: ENVIRONMENTAL IMPACT STUDY.}

\author{
Hicham Khabali². \\ Kamal Targuisti El Khalifi'. \\ Universidad Andelmalek Essaadi, Marruecos.
}

Recibido: marzo, 2012.

Versión final aceptada: abril, 2013.

PALABRAS CLAVE: canteras, estudio de impacto, cordón dunar.

KEY WORDS: querries, impact studies, dunes.

\section{RESUMEN}

La extracción de materiales de construcción, principalmente aquellos que se utilizan para fabricar los conglomerados utilizados en ingeniería civil, construcción y obras públicas, es una práctica generalizada en la región de Kenitra, y se concentran principalmente a lo largo del cordón dunar entre Kenitra y Moulay Bousselham.

Esta industria extractiva se caracteriza por explotar una materia prima poco o simplemente no renovable. Por otra parte, su preservación requiere indispensablemente un conocimiento al detalle de los diversos yacimientos en explotación así como aquellos potencialmente explotables, y sus grados de sensibilidad frente a un uso inapropiado. Se requiere un estudio a fondo de los yacimientos existentes e identificar sus límites ambientales para así definir unas directrices de uso racional y económico de los conglomerados.

El desarrollo de la región norte y la ejecución de proyectos claves en el desarrollo y la gestión de infraestructuras y superestructuras, como son la circunvalación del mediterráneo, el puerto de Tánger-Med, la autovía de Tánger-Larache, la construcción de la ciudad de Al Hoceima y de zonas turísticas como la que podemos encontrar en la ciudad

\footnotetext{
${ }^{1}$ Este artículo se adscribe al Proyecto de Cooperación Internacional PCI 2010 "SIG de usos del suelo en el entorno del SDAU y reserva transfronteriza del Estrecho de Gibraltar", Agencia Española de Cooperación Internacional AECID y Ministerio de Asuntos Exteriores de España.

${ }^{2}$ Investigador del Departamento de Geología de la Universidad Abdelmalek Essaadi.

${ }^{3}$ Catedrático del Departamento de Geología de la Universidad Abdelmalek Essaadi.
} 
de Saaidia, han resultado en una mayor demanda de materiales de construcción, que sigue aumentando, a nivel de toda la región.

Esta necesidad es sin duda importante, pero al mismo tiempo cada vez mayor, y puede resultar en una explotación abusiva, no conforme a la legislación vigente. Esta actividad minera, por la ausencia de instrumentos apropiados para el seguimiento y un plan de gestión que tenga en consideración los recursos disponibles y los ecosistemas y entornos naturales sensibles, puede ser la causa de perjuicios que pueden afectar tanto al medio natural como al sector socio-económico.

Este estudio consiste en la realización de la Evaluación de Impacto Ambiental (EIA) de las canteras en la región de Kenitra. Su propósito es asegurar que las canteras activas, abandonadas o las que se inaugurarán en un futuro no causará ningún daño significativo o irreversible al medio ambiente local y / o regional.

Teniendo en cuenta el gran número de canteras que existen, los impactos que pueden ocasionar y su situación generalmente agrupada, este estudio está diseñado para identificar los riesgos potenciales que suponen, los efectos globales causados las explotaciones en su conjunto así como a nivel especifico.

Este estudio incluye una descripción de las agrupaciones de canteras pertenecientes al área de estudio, una descripción de las condiciones ambientales de la zona y, finalmente, una identificación de los impactos que puedan causar dichas canteras en el medio ambiente.

\section{ABSTRACT}

Extraction of building material, especially those that are used to make the clusters used in civil engineering, construction and public works, is widespread in the region of Kenitra, and are mainly concentrated along the dunes between Kenitra and Moulay Bousselham. The extractive industry is characterized by exploiting a little simply not renewable. Moreover, its preservation requires detailed knowledge of the various existing mines as well as those potentially exploitable, as well as their degree of vulnerability to inappropriate use. It requires a thorough study of existing quarries and minig, to identify environmental limits and drawing guidelines in order to define rational and economical use of clusters.

The development of the northern region and the implementation of key projects in the management of infrastructure and superstructure, such as circumnavigating the Mediterranean port of Tanger-Med, the Tanger-Larache highway, the construction of the city of Al Hoceima and tourist areas such as we can find in the city of Saaidia, have resulted in an increased demand for building materials, which continues increasing at the level of the entire region.

This need is certainly important but at the same time increasing, and may result in an abuse, not according to laws. This mining activity, due to the lack of appropriate tools for

ISSN: 0212-8594 ISSN-e: 2340-2776. № DOI: http://dx.doi.org/10.12795/rea.2013.i30.01

REA 30 (2013):1-26

http://www.publius.us.es/estudios_andaluces 
monitoring and management nor a plan that takes into account the available resources and ecosystems and sensitive natural environments, may be causing damage that can affect both the environment and socioeconomy.

This paper faces the performance of the Environmental Impact Assessment (EIA) of the quarries in the region of Kenitra. Its purpose is to ensure that active quarries, either abandoned or to be opened in the future, will not cause any significant or irreversible damage to the local/regional environment.

Considering the large number of existing quarries, the impacts that may result and generally grouped situation, this study is designed to identify potential risks caoused by the the overall effects from mining and quarries as a whole as well as an specific level.

This study includes a description of the groups of quarries belonging to the study area, a description of the environmental conditions of the area and, finally, an identification of the impacts caused by these quarries on the environment.

ISSN: 0212-8594 ISSN-e: 2340-2776. № DOI: http://dx.doi.org/10.12795/rea.2013.i30.01

REA 30 (2013):1-26

http://www.publius.us.es/estudios_andaluces 


\section{MARCO GEOGRÁFICO Y GEOLÓGICO.}

La región de Kenitra se extiende por la parte noroeste de Marruecos, ocupando un área de de 4000 km2. Esta zona pertenece al ámbito de la cuenca de Sebou ocupando su parte occidental. Limita al oeste con el Océano Atlántico, al sur con la cuenca de Mamora y de norte a este por las colinas margas prerifeñas.

Figura 1: Ubicación de la región de Kenitra.

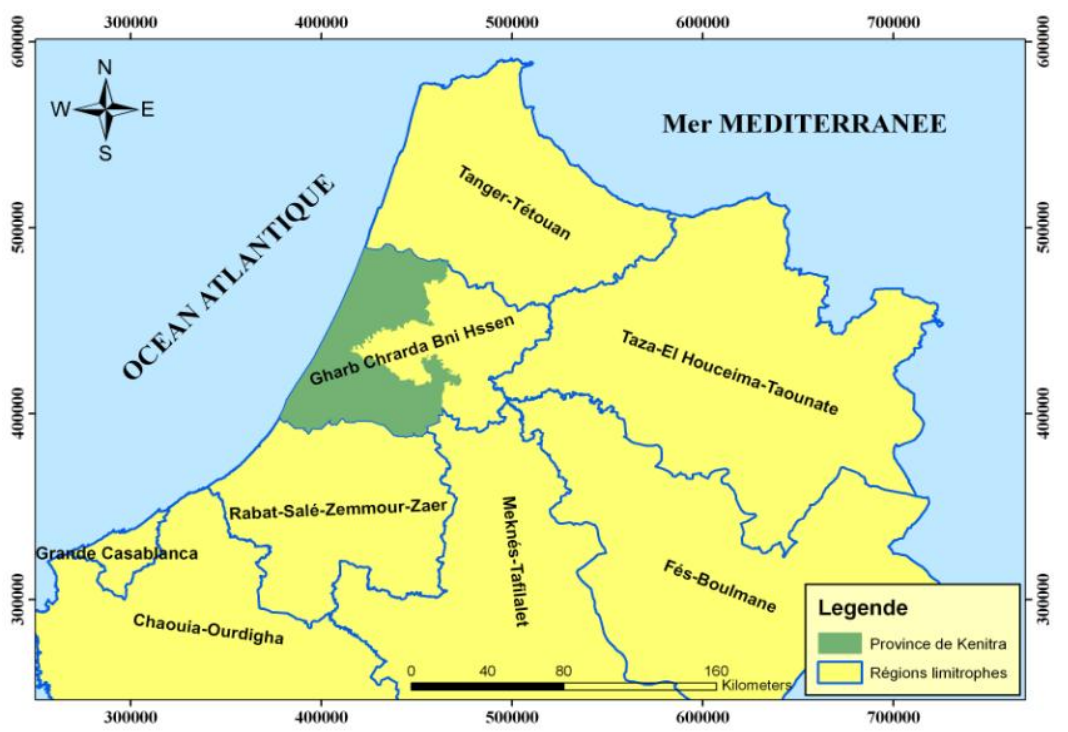

Fuente: Elaboración propia.

A nivel geológico, el área de estudio corresponde a una zona que delimita a dos grandes conjuntos estructurales:

- El Rif por la zona norte hasta el este, con forma arqueada y plegada, perteneciente a los Alpes. Estas formaciones avanzan en forma de pliegues de cabalgamiento desde el NE hacia el SO.

- La Meseta Central por la zona sur, perteneciente a la cadena hercínica, y que se introduce hacia el norte en la cuenca de Gharb Mamora.

\section{Paleozoico (era Primaria):}

El basamento hercínico de la Meseta no llega a aflorar en la llanura de Gharb, sino que se encuentra cubierto por discordancias angulares de estratos secundarios y terciarios, se hunde y avanza hacia el norte interrumpiéndose al contactar con la zona prerifeña por un sistema de fallas limítrofes (Michard, A., 1976). 
Mesozoico (era Secundaria):

Al igual que en el Paleozoico, en el Mesozoico tampoco se producen afloramientos en la llanura de Gharb, sus capas se extienden en profundidad y solo aparecen en los límites de la Meseta así como al sur de la zona prérifeña con formaciones liásicas de piedras calizas y dolomitas.

Cenozoico (era Terciaria):

\section{El Paleógeno:}

Aflora en la zona prerifeña por el norte y por el noreste de la cuenca del Gharb, consiste esencialmente en flysch, margas y conglomerados.

\section{El Mioceno:}

Constituye la base de sustrato genérica de la llanura de Gharb, formada por una potente serie de margas azules y grises, con profundidades de unos $100 \mathrm{~m}$ en su parte exterior hasta 250 metros o más en su parte central. Estas margas Estas margas forman el acuitardo que define los niveles de base de los acuíferos del Gharb.

\section{El Plioceno:}

Se caracteriza principalmente por depósitos marinos en el interior de una serie regresiva que comienzan con limos y arenas muy finas, calizas arenosas y que culminan en la parte superior con conglomerados.

\section{El Villafranquiense y principios del Pleistoceno:}

La llanura de Gharb tomó su forma en la cuenca de subsidencia durante el periodo Villafranquiense (Aberkan, M., 1989). Durante este período los depósitos continentales aluviales, formados por guijarros y grava, se depositaron principalmente en la parte norte y este de la llanura, siguiendo este proceso a lo largo del Cuaternario. Según los estudios realizados, los depósitos del periodo Villafranquiense y del Cuaternario pueden alcanzar $250 \mathrm{~m}$ de espesor, dando lugar al grado de hundimiento que presenta.

\section{El Cuaternario medio:}

\section{El Amiriense:}

El Amiriense se caracteriza por facies de arcilla arenosa en el perímetro del Gharb, las formaciones comienzan con series de arenosas o de gravas en la base y terminan en depósitos de arcillas limosas y acumulaciones de piedra caliza. Estas formaciones se pueden observar en la perforación de Dar Gueddari a 50 m de espesor (COMBE 1967).El

ISSN: 0212-8594 ISSN-e: 2340-2776. № DOI: http://dx.doi.org/10.12795/rea.2013.i30.01 
Amiriense también se puede observar en el margen izquierdo del Oued Beht por la presencia de conglomerados de cantos rodados en su curso superior a de sedimentos calcáreos blanquecinos (Aberkan,M., 1989). En los límites exteriores de la cuenca, el Amiriense apenas está presente.

\section{El Tensifiense:}

Por encima del Amiriense se encuentran formaciones pertenecientes al Tensifiense que se caracterizan por depósitos de gravas entre arenas más o menos arcillosas de unos $60 \mathrm{~m}$ de espesor.

\section{El Soltaniense:}

Representa la última capa del Cuaternario Medio. A diferencia de las anteriores, los depósitos son de menor espesor pero de mayor extensión superficial y están presentes por todas el Gharb.

Sus facies se reconocen principalmente por ser finas, de carácter calizo con coloración roja y amarilla y con gravas en la base.

Nota: Los niveles más gruesos del Soltaniense constituyen el nivel superior del acuifero a media profundidad mientras que los niveles arcillosos finos constituyen el nivel freático del Gharb (Kassimi, 1992).

\section{El Cuaternario tardío (Gharbiense):}

Los depósitos del Cuaternarios tardío, también conocido por Gharbiense, cubren toda la llanura del Gharb, que se caracterizan por formaciones arcillosas (Tirs) en el Gharbiense anterior, y formaciones más o menos arenosas (Dess) en el Gharbiense reciente.

\subsection{GEOMORFOLOGÍA.}

La morfología de la llanura Gharb se asemeja a una amplia cuenca donde el $90 \%$ de su extensión es inferior a una altura de $20 \mathrm{~m}$. En esta cuenca se distinguen dos unidades principales (Bryssine, 1992) desde el Oeste hacia el Este:

-La zona costera arenosa (o del Sahel).

- La llanura de inundación.

ISSN: 0212-8594 ISSN-e: 2340-2776. № DOI: http://dx.doi.org/10.12795/rea.2013.i30.01

REA 30 (2013):1-26

http://www.publius.us.es/estudios_andaluces 
La zona costera se reconoce por una franja paralela a la costa que separa la llanura de inundación con el Océano Atlántico y está representada por un conjunto de sistemas dunares e interdunares. En esta zona se distinguen de oeste a este, tres unidades:

- El cordón dunar.

Se trata de un conjunto de dunas altas consolidadas, continuas y paralelas a la costa, cuya altitud se encuentra generalmente entre 50 y $60 \mathrm{~m}$.

Estas dunas se extienden sobre una extensión de unos $5 \mathrm{Km}$. por la zona Sur y sobre unos pocos cientos de metros por la zona Norte.

- Merjas costeras (Lagunas costeras).

Se trata de una serie de Merjas (lagunas) que se formaron en un surco interdunar en un nivel inferior del Cordón dunar, se extienden sobre $25 \mathrm{Km}$. de longitud y de 1 a $2 \mathrm{Km}$. de amplitud.

-Zonas de dunas y planicies dunares interiores.

Es el área más extensa de la zona costera, constituye una intercalación entre las Merjas costeras o el Cordón dunar por el Oeste y la llanura de inundación por el Este, su altitud es de entre 5 a $15 \mathrm{~m}$.

-Área de la llanura de inundación.

Es el área de la planicie con forma de cuenca plana y baja con una altitud muy baja en su parte central y de unos 50 metros en su limite exterior por el lado Este. Se divide en tres áreas:

- Áreas de diques

Son áreas elevadas que se encuentran en los bordes de los Oueds (ríos) Sebou y Beht y se extienden sobre aproximadamente el $29 \%$ de la llanura.

- Las zonas bajas de las antiguas Merjas

Son amplias depresiones de antiguas Merjas, representan el $16 \%$ de la llanura y ocupan las posiciones más bajas.

- Las zonas intermedias

Cubren aproximadamente el $40 \%$ de la llanura de inundación y se encuentran entre los diques y las zonas bajas de las antiguas Merjas, con una altura de 10 a $20 \mathrm{~m}$. Corresponden a las zonas arcillosas (Tirs) que dominan la mayor parte de Gharb.

ISSN: 0212-8594 ISSN-e: 2340-2776. № DOI: http://dx.doi.org/10.12795/rea.2013.i30.01

REA 30 (2013):1-26

http://www.publius.us.es/estudios_andaluces 


\subsection{EDAFOLOGÍA.}

El suelo en la llanura del Gharb es muy diverso en cuanto a su textura y su naturaleza. Se encuentran varios tipos:

Suelos arenosos "Rmel"

Estos suelos de textura muy arenosa y estructura gruesa ocupan la mayor parte de la zona costera (el cordón dunar y las dunas interiores). Estos suelos profundos y homogéneos son pobres en materia orgánica y se caracterizan por una excesiva permeabilidad.Yacen sobre un subsuelo de alta permeabilidad formada por arenas y areniscas (cordón dunar).

Los suelos negros "Toug"

Suelos con texturas que varían entre el arenoso-limoso y el arcilloso-limoso perteneciente a la clase de suelos hidromórficos, se encuentran sobre todo en las zonas bajas y en las depresiones interdunares.

Estos suelos son más o menos permeables, y su contenido en materia orgánica es relativamente alto.

\section{Suelos tipo Dehs y Hamri}

Suelos isohúmicos de texturas que van de limosa a limoso-argilosa, son bastante permeables y cuyo contenido en materia orgánica es bajo. Representan los mejores suelos para el riego en el ámbito de la llanura del Gharb. Se encuentran principalmente en los diques de los Oueds Sebou y Beht.

Los Tirs

Pertenecen a los Vertisoles, suelos muy arcillosos en toda su profundidad y son muy poco permeables. Ocupan las áreas entre los diques y las tierras bajas de Merjas antiguas

Los suelos de antiguas Merjas

Corresponden a vertisoles hidromórficos muy arcillosos y de mayor salinidad a mayor profundidad. La permeabilidad de estos suelos es muy débil y su contenido en materia orgánica se encuentra entre el 2 y el $3 \%$.

\subsection{CLIMATOLOGÍA E HIDROLOGÍA DE LA ZONA.}

La llanura del Gharb está situada en una zona de clima mediterráneo, donde existen dos estaciones principales:

ISSN: 0212-8594 ISSN-e: 2340-2776. № DOI: http://dx.doi.org/10.12795/rea.2013.i30.01

REA 30 (2013):1-26

http://www.publius.us.es/estudios_andaluces 
Un invierno fresco, húmedo y lluvioso generado por la llegada de masas de aire polar yun verano caluroso y muy seco debido a la aparición de una masa de aire tropicalTodo ello sometido a la influencia del desplazamiento del anticiclón de las Azores (EL Gharbaqui, A., 1987).

Según la clasificación bioclimática de Emberger, la cuenca del Gharb pertenece al piso sub-húmedo de invierno templado en su zona occidental costera influenciada por el Océano Atlántico y al piso semi-árido en el interior de la llanura y en su zona oriental.

En términos hidrológicos, varios ríos atraviesan la cuenca del Gharb, siendo el más importante el Oued Sebou y sus afluentes Beht y Ouergha. La cuenca se caracteriza también por la presencia de algunos lagos y varios Merjas.El Oued (río) más importante que caracteriza a la llanura del Gharb es el río Sebou, que proviene del Medio Atlas y desemboca en el Océano Atlántico, el cual traza un recorrido dotado de meandros de una longitud de unos $223 \mathrm{~km}$.El Sebou recibe varios afluentes, siendo los principales:

- El Oued Ouergha en la margen derecha responsable de la descarga de aproximadamente dos terceras partes de su volumen de agua;

- El Oued Beht en la margen izquierda.

El aporte que recibe de agua la cuenca se estima en 4800 millones de m3 por año de los cuales $2.784 \mathrm{Mm} 3 /$ año son drenados por el Ouergha, $616 \mathrm{Mm} 3 /$ año por el tramo alto del Sebou y hasta $360 \mathrm{Mm} 3 /$ año por el Beht. (Según la Agencia Hidrológica de la Cuenca del Sebou AHCS). El Gharb también es atravesado por otros Oueds, tales como: Oued Smento, Rdeme, Mda, Tihili... etc.

En la llanura del Gharb, se han construido y equipado varias presas ya sea para la protección contra las inundaciones o para su uso en riego y como agua potable.Las principales presas son:

- La presa de Al Wahda en el Oued Ouergha, que desempeña un papel en la protección contra las inundaciones y el riego de una gran parte de la llanura. Esta presa tiene una capacidad de $3,8 \mathrm{mil} \mathrm{m}^{3}$.

- La presa de El Kansera en el Oued Beht, su capacidad de almacenamiento es de 270 millones de $\mathrm{m} 3$, destinado principalmente para el riego.

- La presa de "Garde" en el Oued Sebou que además de su función para el riego, fue diseñada para proteger contra la subida de aguas saladas en periodos de marea alta

ISSN: 0212-8594 ISSN-e: 2340-2776. № DOI: http://dx.doi.org/10.12795/rea.2013.i30.01

REA 30 (2013):1-26

http://www.publius.us.es/estudios_andaluces 
así como para elevar el nivel del agua y permitir el correcto funcionamiento de las estaciones de bombeo en el Sebou.

En la cuenca del Gharb se encuentra también un abundante número de lagunas y Merjas entre las cuales las más importantes son:

- Merja Zerga al norte de la cuenca, que aun permanece;

- Merja Daura al norte de la ría de Sebou

- La laguna de Sidi Boughaba al sur,

- Y muchos otras Merjas en la zona costera temporal o permanente.

En la cuenca del Gharb, se distinguen dos acuíferos superpuestos:

- El acuífero superior.

Su nivel freático es de bajo potencial hidráulica y de mala calidad (con un alto grado de salinidad), se encuentra contenida en la formación de limo-arcillosa superficial del Cuaternario reciente de muy baja permeabilidad.La pared de este acuífero es difícil de definir, según Combe, M. et al (1975), su capa inferior se encuentra entre 8 y $15 \mathrm{~m}$ de profundidad y corresponde al complejo arcillosolimoso (Amiriense y Soltaniense). La parte superficial del acuífero se compone de formaciones de arcilla y de limo del Gharb. Sus aportes vienen por la infiltración de las aguas de lluvia y de inundaciones.

- El acuífero profundo.

Es un acuífero multicapa con una gran capacidad de recarga que se libera a nivel de la zona costera y en sus límites exteriores. El agua fluye a través de terrenos de la edad Plio-Cuaternaria. Su capa inferior se caracteriza por una potente serie de margas azules del Mioceno superior. Su cubierta se compone de la capa de arcilla de la formación superior, por lo general se encuentra a una profundidad de entre 20 y $-40 \mathrm{~m}$ en su parte central y en algunos puntos llega a superar los $100 \mathrm{~m}$. de profundidad.

En la zona costera, el acuífero se compone de un nivel de arena de arenisca a la altura del cordón dunar y de un nivel arenoso en las dunas interiores, en estas áreas el acuífero libera sus aguas en una capa subterránea poco profunda, por lo general a una profundidad inferior a los $10 \mathrm{~m}$ y de 10 a $40 \mathrm{~m}$ en la zona del cordón dunar. La recarga de aguas subterráneas en la zona costera proviene únicamente de la infiltración de las precipitaciones.

Predominan los procesos de infiltración mientras que los de escorrentía son casi inexistentes. En la llanura propiamente dicha, el acuífero acumula agua y esta fluye

ISSN: 0212-8594 ISSN-e: 2340-2776. № DOI: http://dx.doi.org/10.12795/rea.2013.i30.01

REA 30 (2013):1-26

http://www.publius.us.es/estudios_andaluces 
a través de la formaciones del Cuaternario temprano y del Cuaternario medio donde predominan facies de gravas separadas por capas arcillosas-limosas (en su vertiente Oriental) y facies de carácter arenosos, de areniscas y calcarenitas separadas por capas arcillosas-limosas (por la zona costera y Meridional en la zona de Mamora).

La recarga de aguas subterráneas viene dada por la infiltración del agua de lluvia por los bordes de la llanura (Mamora al sur, las dunas costeras al oeste y las formaciones del Plio-Villafranquiense al norte y al este.

\section{METODOLOGÍA Y TÉCNICAS.}

Con el fin de disponer de un gran número de datos relevantes para identificar los principales operadores así como localizar lugares de muestreo, se han realizado investigaciones preliminares a nivel de la administración así como los servicios centrales y regionales competentes.

La información obtenida durante las investigaciones preliminares proviene de los estudios e investigaciones existentes y los documentos técnicos y administrativos proporcionados por las partes interesadas. El análisis de estos documentos ha permitido desarrollar una base de datos de información preliminar sobre las canteras existentes, su ubicación, el tipo y su identidad.

En cuanto al trabajo de campo, basándonos en los datos obtenidos (por escrito o verbalmente), y con el propósito de actualizar y completar dicha información, se han llevado a cabo visitas sobre el territorio a nivel de los municipios afectados por la actividad extractiva (reglada o indiscriminada).

Para la obtención de datos referidos a la actividad extractiva reglada, al estado de las zonas mineras y sus zonas circundantes se realizaron encuestas a los empleados de las canteras por medio de un cuestionario. Al igual que en cualquier tipo de inventario, se encontraron ciertas complicaciones, entre las cuales merece la pena citar:

- Ausencia de las personas a entrevistar a nivel de las canteras.

- Falta de señalización que delimiten las canteras.

- Ausencia de la placa de identificación del operador de la cantera.

ISSN: 0212-8594 ISSN-e: 2340-2776. № DOI: http://dx.doi.org/10.12795/rea.2013.i30.01

REA 30 (2013):1-26

http://www.publius.us.es/estudios_andaluces 
- Reticencia de algunos operadores en comunicar la información que se les consulta, a destacar los datos sobre los volúmenes extraídos por día o el número promedio de viajes al día.

- Falta de accesibilidad a los arenales de Kenitra.

A pesar de estas complicaciones, se han alcanzado plenamente los objetivos de este estudio.

El impacto de la extracción de arena en el cordón dunar se ha evaluado principalmente en su morfología. Así, a efectos de este estudio, la morfología del cordón dunar fue reconstruida a partir de imágenes satélite durante el período comprendido entre 1987 y 2001.

Estas imágenes fueron adquiridas por el sensor multiespectral Thematic Mapper con una resolución espacial de $30 \mathrm{~m}$, dichas imágenes fueron posteriormente georeferenciadas y ortorectificadas. Las correcciones geométricas se hicieron para minimizar el error en el análisis de la evolución del cordón dunar a partir de las imágenes satélites utilizadas.

Las correcciones aplicadas a estas imágenes son la georeferenciación, el remuestreo, la ortorectificación, el mosaico, reproyección y mejora radiométrica.

Para el estudio de la evolución del cordón dunar se ha utilizado un estudio con el propósito de informar a los los responsables políticos así como a un grupo de ciudadanos cuyo deseo sea tener una idea de la velocidad a la que transcurren las actividades de explotación y con el fin de poder defender sus derechos y participar en la protección del medio ambiente

El análisis de la evolución del cordón dunar se basa en la interpretación de imágenes satélite sobre las que se ha compilado la información. El análisis ha sido objeto de dos etapas de generalización. La primera en la interpretación de las fotos por satélite con el fin de definir el tamaño mínimo de la cartografía. El segundo, cuando dicha información se reinterpretó para ser aplicada a gran escala.

Esta cartografía puede utilizarse también como un documento histórico que muestra el uso del suelo en un período específico de tiempo y como información de base para la planificación regional. Para ello, podemos utilizarla conjuntamente con otra cartografía (sobre la potencialidad de los suelos...).

ISSN: 0212-8594 ISSN-e: 2340-2776. № DOI: http://dx.doi.org/10.12795/rea.2013.i30.01

REA 30 (2013):1-26

http://www.publius.us.es/estudios_andaluces 
Mediante el análisis de imágenes satelitales y su superposición, es posible identificar, cuantificar y realizar un seguimiento de la variación del cordón dunar, en términos de superficie pero no a nivel de potencial. Estos resultados ofrecen por lo tanto la posibilidad de ejercer un mejor control de futuras explotaciones areneras, por lo que constituyen una herramienta indispensable para administradores y usuarios de áridos.

\section{DECRIPCIÓN DE LAS EXPLOTACIONES.}

La diversidad de materiales de construcción que se encuentran en la región del Gharb (provincia de Kenitra) es debida a la apertura de aproximadamente 98 canteras de las cuales cuarenta se encuentran activas. Estas canteras proporcionan los conglomerados destinados principalmente a la producción industrial (cemento, ladrillo, azulejo) o la producción de materiales de construcción (arena, piedras, etc....). Esta cifra es considerable en comparación con la media nacional que se encuentra en unas cincuenta canteras por región. En la actualidad, las canteras existentes se distribuyen según sus yacimientos de acuerdo con la siguiente tabla:

Tabla 1 Inventario de canteras en la región de Kenitra.

\begin{tabular}{|l|l|c|}
\hline Tipo de cantera & \multicolumn{1}{|c|}{ Estado } & Total \\
\hline \multirow{2}{*}{ Aluviones de altas terrazas } & Abandonadas & 24 \\
\cline { 2 - 3 } & Activas & 3 \\
\cline { 2 - 3 } & Detenidas & 1 \\
\hline Aluviones del Oued & Abandonadas & 3 \\
\hline Arcilla & Activas & 1 \\
\hline \multirow{2}{*}{ Calcarenitas } & Abandonadas & 9 \\
\cline { 2 - 3 } & Detenidas & 7 \\
\hline \multirow{2}{*}{ Arenas } & Abandonadas & 27 \\
\cline { 2 - 3 } & Activas & 4 \\
\cline { 2 - 3 } & En uso & 16 \\
\cline { 2 - 3 } & Detenidas & 98 \\
\hline
\end{tabular}

Fuente: Elaboración propia.

En la región del Gharb, a pesar de la diversidad de los yacimientos existentes, el $97 \%$ de los conglomerados se obtienen a partir de rocas aluviales principalmente provenientes del cordón dunar y sólo el 3\% de otros áridos (piedra, mármol y piedra caliza).

Los materiales extraídos son muy variables, desde mármol hasta arena de alta calidad. Estos conglomerados se destinan principalmente (95\%) a la producción de mortero y

ISSN: 0212-8594 ISSN-e: 2340-2776. № DOI: http://dx.doi.org/10.12795/rea.2013.i30.01

REA 30 (2013):1-26

http://www.publius.us.es/estudios_andaluces 
hormigón (pretensado o para su uso directo, así como otros tipos). Los demás materiales se destinan a otros tipos de trabajos, principalmente carreteras y la red viaria en general.

El diagnóstico de los lugares donde se lleva a cabo la actividad extractiva y de procesamiento de materiales, ha permitido identificar algunas deficiencias a nivel institucional, organizativo, normativo debido a una explotación no racional, incluso a veces caótica, de los materiales. Estas observaciones se han identificado en varios niveles:

- A nivel del territorio: La ausencia de una delimitación jurídica de ciertas parcelas pertenecientes al Dominio Hidráulico Público, terrenos públicos o pertenecientes al ámbito de Aguas y Bosques, ha dado lugar a que en algunas explotaciones mineras se hayan producido conflictos con respecto a la titularidad de los terrenos fomentando una actividad extractiva no reglada y anárquica. Una delimitación territorial facilitaría el control de las canteras y potenciaría de alguna manera la organización de este sector.

- A nivel organizativo: Nos encontramos con:

- Falta de inspecciones periódicas.

- Falta de cumplimiento con las medidas de control y seguimiento de los distintos tipos de canteras "temporales y permanentes".

- Falta de estandarización de los procedimientos para la concesión de licencias de explotación por parte del organismo regulador.

- La falta de coordinación entre los municipios afectados con la administración competente (DPE, Agencia de la Cuenca Hidráulica, etc.).

La mejora de las medidas de control y seguimiento para cada tipo de cantera, acompañado por una estandarización del procedimiento de concesión de autorizaciones permitiría, además de una recaudación de impuestos y cánones, controlar los volúmenes de materiales extraídos y las modalidades de explotación. Estas medidas tendrían por objeto evitar cualquier tipo de infracción provocada por el incumplimiento de las cláusulas definidas en las especificaciones técnicas de las explotaciones.

De manera similar, y en ausencia de un plan de asignación de los recursos extraídos según las necesidades y oportunidades existentes, se produce generalmente a una concentración de actividades extractivas a nivel territorial muy reducido y en zonas que parecen ser vulnerables. Esta presión tiene generalmente como resultado un agotamiento

ISSN: 0212-8594 ISSN-e: 2340-2776. № DOI: http://dx.doi.org/10.12795/rea.2013.i30.01

REA 30 (2013):1-26

http://www.publius.us.es/estudios_andaluces 
de los recursos potencialmente disponibles y la aparición de daños ambientales (afloramientos de capas freáticas, etc.).

Sin embargo, la aparición de estos daños suele conllevar el cese definitivo de la actividad de la cantera. A pesar de que este tipo de iniciativa esté dirigida a salvaguardar el medio ambiente como es el caso de las canteras de arenas de Ben Mansour, las de piedras de Sidi Taibi, y lasque se encuentran en las terrazas altas de Dar Bel Amri, también son responsables de que se desarrolle una actividad minera anárquica, que sigue dando como resultado efectos negativos sobre la seguridad de la población y las instalaciones públicas (puentes, tendidos eléctricos, casas, caminos, etc.). Por este motivo el cierre de algunas minas debe ir acompañado por la apertura de nuevas canteras en la zona siempre teniendo en cuenta el potencial existente, su impacto sobre el marco socio-económico de la zona en términos de ingresos, creación de empleo, el desarrollo de la zona ... etc.).

Figura 2: Localización geográfica canteras en la región de Kenitra.

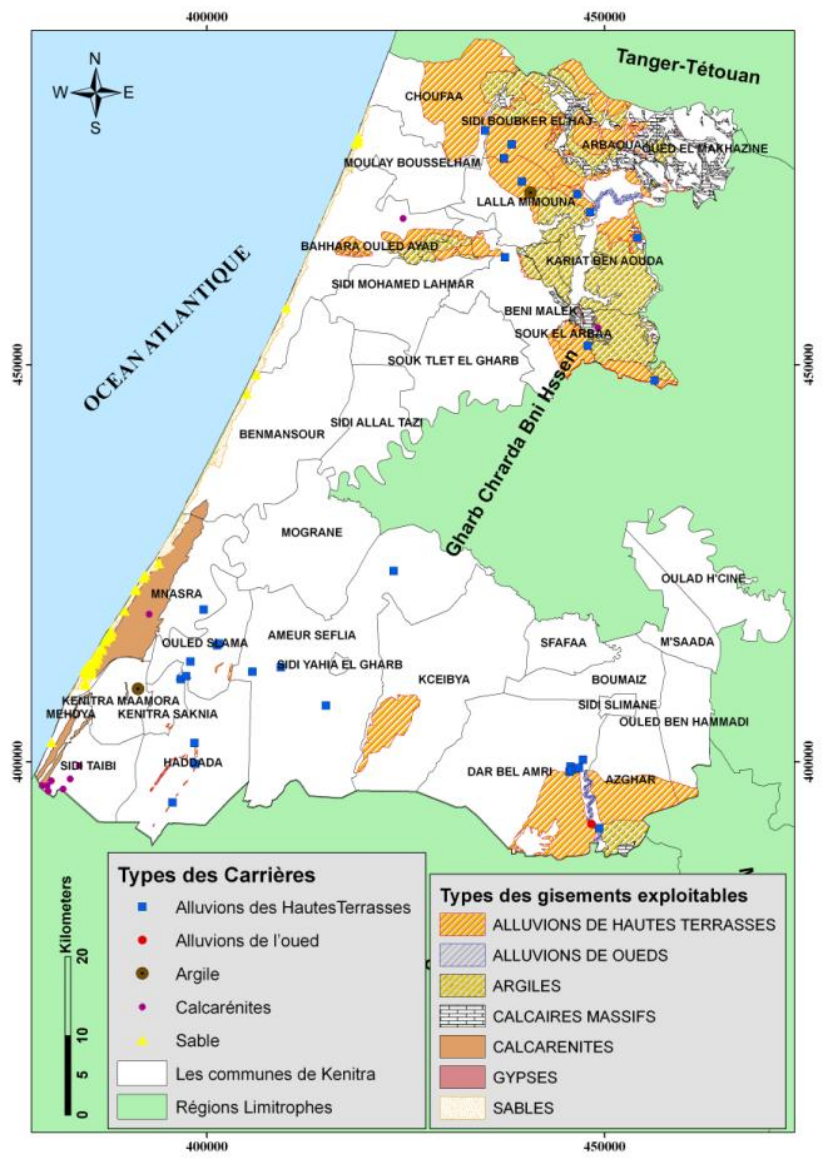

Fuente: Elaboración propia.

ISSN: 0212-8594 ISSN-e: 2340-2776. № DOI: http://dx.doi.org/10.12795/rea.2013.i30.01

REA 30 (2013):1-26

http://www.publius.us.es/estudios_andaluces 
- En el ámbito normativo:

En algunos lugares de la zona estudiada, la explotación de canteras viene acompañada de ciertas infracciones, entre las que destacan principalmente:

- Una sobreexplotación en profundidad, sobre todo en el caso de algunas explotaciones de arenas que presentan cavidades con pendientes escarpadas.

- Una subestimación de los volúmenes declarados.

- La no recuperación de zonas explotadas: 2/3 de las canteras son abandonadas sin la realización de ningún tipo de medidas de rehabilitación o recuperación de las condiciones iniciales en las que se encontraban (falta de vallas, pendientes pronunciadas, grandes profundidades), lo cual ocasiona la aparición de efectos residuales negativos.

- La transformación de algunas canteras abandonadas en vertederos, como es el caso de las canteras de Lalla Mimouna y la de Sfaya. La mayoría de estas canteras deben ser considerados como lugares vulnerables, medios expuestos y permeables en los que el agua puede infiltrarse y circular rápidamente, llegando a acuíferos de poca profundidad (dependiendo de la topografía) que sirven de fuentes y/o zonas de captación. Por lo tanto no son espacios adecuados para albergar cualquier tipo de actividad contaminante.

\section{IDENTIFICACIÓN DE LA ACCIÓN DE LAS CANTERAS.}

El propósito de esta sección es presentar los impactos provocados por los tipos de canteras de manera a que se puedan tomar medidas a gran escala para garantizar su inserción en su entorno más inmediato y cercano poniendo en práctica las medidas de mitigación, rehabilitación y reconstrucción necesarias.

La poca abundancia a nivel regional de este tipo de recurso (areniscas, calizas masivas y calcarenitas) ha dado lugar a una alta concentración de este tipo de explotaciones en Sidi Taibi, donde se han censado un total de 10 canteras de calcarenita que se encuentran en la actualidad abandonadas.

El abandono de las canteras de Sidi Taibi, sin ningún tipo de rehabilitación ni recuperación de su estado inicial, es la principal fuente de impactos detectados. Estas canteras son actualmente grandes cavidades que acaban albergando restos contaminantes de diferentes actividades (ganadería, agricultura, etc.) pudiendo ocasionar una contaminación irreversible de la capa freática de Maamora, principal aporte en agua potable a las poblaciones locales abastecidas por la zona de captación de "Sidi Taibi"

ISSN: 0212-8594 ISSN-e: 2340-2776. № DOI: http://dx.doi.org/10.12795/rea.2013.i30.01

REA 30 (2013):1-26

http://www.publius.us.es/estudios_andaluces 
En los casos en los que estas cavidades se dan en zonas kársticas con un alto grado de fisuración y en las que las aguas fluyen rápidamente, sin ser por procesos de filtración, alcanzando acuíferos más o menos profundos (dependiendo de la topografía) con sus respectivas zonas de descarga y de captación, deben considerarse como áreas de alta vulnerabilidad y por lo tanto no constituyen los lugares más favorables para albergar cualquier tipo de actividad contaminante o de vertido.

El cierre de las canteras de Sidi Taibi resultaba en un impacto positivo sobre el medio ambiente, pero también en un gran impacto negativo a nivel de la economía local y la mano de obra. Esto provocó la aparición de una actividad minera caótica con efectos adversos sobre la seguridad de las personas e infraestructuras, a pesar de movilizar un volumen bajo de materiales. La precariedad de la actividad extractiva y el incumplimiento de las normas de extracciones (extracciones en galerías, con proximidad a viviendas, a zonas agrícolas y forestales, etc.) ha dado lugar impactos importantes vinculados a:

- Riesgos de accidentes, especialmente para las poblaciones de Oulad N'sar.

- La desestabilización de viviendas en Oulad N'sar.

- Impactos sobre el terreno agrícola circundante.

- Degradación de los bosques.

- Deterioro de las instalaciones públicas (línea de alta tensión).

Además de estos impactos negativos, se han identificado otros retos socio-económicos fundamentales. Los empleos vinculados a la extracción de piedras ornamentales es muy importante a nivel de la economía local (concierne a unas 200). El aumento continuo de la demanda por parte de las regiones vecinas así como el potencial existente de materia a explotar podría incurrir en un aumento de esta actividad o una diversificación de los materiales a nivel del mercado.

La mayoría de las canteras clausuradas de Sidi Taibi, están sin cercar y sus cavidades presentan pendientes escarpadas y una profundidad que varían entre los 10 y $20 \mathrm{~m}$, constituyendo un peligro inminente para la seguridad de la población circundante.

También destacar que algunas canteras de áridos que se encuentran abandonadas a día de hoy en Sidi Taibi a las que no se les ha realizado ningún tipo de recuperación poseen una extensión considerable y se encuentran dispuestas de manera que resultan visibles

ISSN: 0212-8594 ISSN-e: 2340-2776. № DOI: http://dx.doi.org/10.12795/rea.2013.i30.01

REA 30 (2013):1-26

http://www.publius.us.es/estudios_andaluces 
desde la carretera principal. Esta ruta es muy transitada y por lo tanto existe un gran impacto a nivel paisajístico.

Las canteras de aluviones de terrazas altas Estas canteras, generalmente de mediana a pequeña escala, consisten en explotaciones con actividad intermitente y fluctuante en función de las necesidades a nivel locales, para el sector de la construcción y / o rehabilitación.

En la región del Gharb, del total de 29 canteras de terrazas altas identificadas, únicamente dos se encuentran en funcionamiento. Las autoridades no autorizan actividades extractivas indiscriminadas. Esta es sin duda una de las causas de la aparición de algunas prácticas mineras ilegales que se producen a nivel de los núcleos urbanos de Lalla Mimouna, de Haddada, de Bni Malek y Dar Bel Amri. La importancia de este tipo de impacto es sin duda importante.

La principal fuente de impactos identificados a nivel de estas canteras es la explotación en profundidad de los horizontes pertenecientes al villafranquiense en las terrazas altas. En consecuencia estas canteras presentan cavidades con una profundidad considerable y ocurren en ellas afloramientos de agua en algunas zonas de recarga especialmente en Lalla Mimouna y Dar Bel Amri (a unos 10-20m).

Destacar también que algunas de estas canteras (Lalla Mimouna, Bni Malek) se convierten en vertederos y en consecuencia pueden causar impactos negativos en la calidad del agua a causa de los volúmenes asociados a los procesos de lixiviado que se generan. Otros impactos de intensidad media a destacar son aquellos asociados al tráfico de vehículos, el ruido y el polvo así como sobre el paisaje.

- Canteras de arena.

Las canteras de arena en Kenitra explotan las formaciones marinas del Cuaternario tardío (cordón dunar) que se encuentran a lo largo de la costa atlántica. Este sistema está formado por una serie de dunas altas poco consolidadas, continuas y paralelas a la costa.A día de hoy, de las 55 canteras de arena identificadas 27 son productivas. Son de gran envergadura y se concentran cercanas a las comunidades rurales de Mnasra (douares Chlihat Oulad-Berjel, Fzara-Oulad-Assal Oulad Ziane) y Moulay Bousselham (CR Riah Zaouia).

ISSN: 0212-8594 ISSN-e: 2340-2776. № DOI: http://dx.doi.org/10.12795/rea.2013.i30.01 REA 30 (2013):1-26 
- Canteras de arcilla.

En la región del Gharb, se han inventariado tres canteras de arcilla: dos en Daya Safaya (distrito urbano de Kenitra)y una en Douar Maiden al norte de la localidad rural de Lalla Mimouna.

Estas canteras se encuentran activas y explotan recursos de arcillas y margas del Tortoniense para la producción de ladrillos y baldosas de cerámica.

En Daya Safaya, ciertas cavidades de las minas de arcilla se convierten en vertederos incontrolados de residuos pudiendo ser el origen de un deterioro de la calidad de vida de la población, de la calidad del aire y del paisaje, dada su ubicación en una zona de humedal y un camino muy transitado del área urbanizada circundante.

En cuanto a los recursos hídricos se refiere, existe una elevada sensibilidad ambiental, pero nos encontramos con que el impacto es moderado debido a la capacidad de impermeabilización de la arcilla y su extensión a nivel local y por ello el impacto se considera moderado. En cuanto al aspecto visual, el impacto se considera grave.

Por otro lado, la cantera de arcilla de Lalla Mimouna opera en un campo de uso tradicional agrícola, provocando un gran impacto negativo sobre el valor de mercado de las tierras agrícolas cercanas y sobre la calidad de los productos agrícolas por la liberación de polvos a causa de la actividad extractiva.

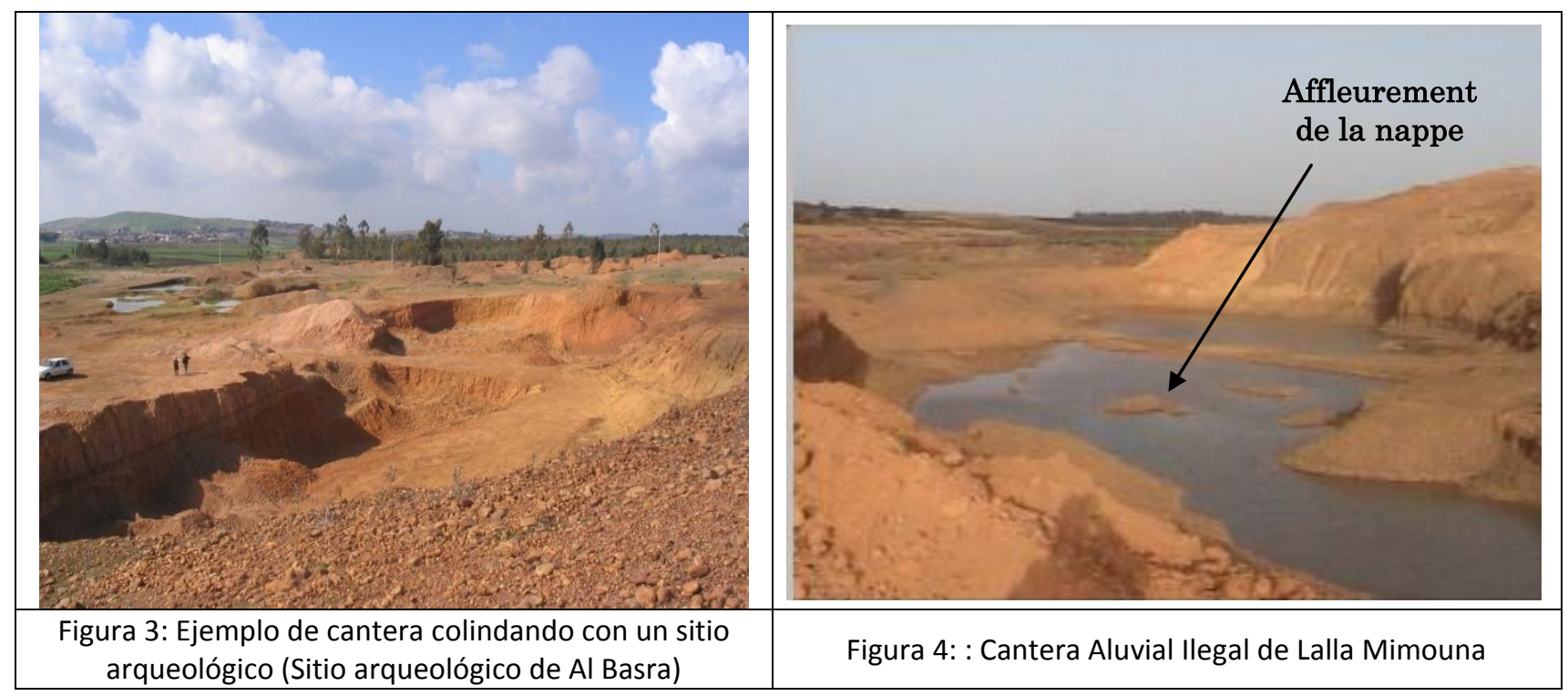

ISSN: 0212-8594 ISSN-e: 2340-2776. № DOI: http://dx.doi.org/10.12795/rea.2013.i30.01

REA 30 (2013):1-26

http://www.publius.us.es/estudios_andaluces 


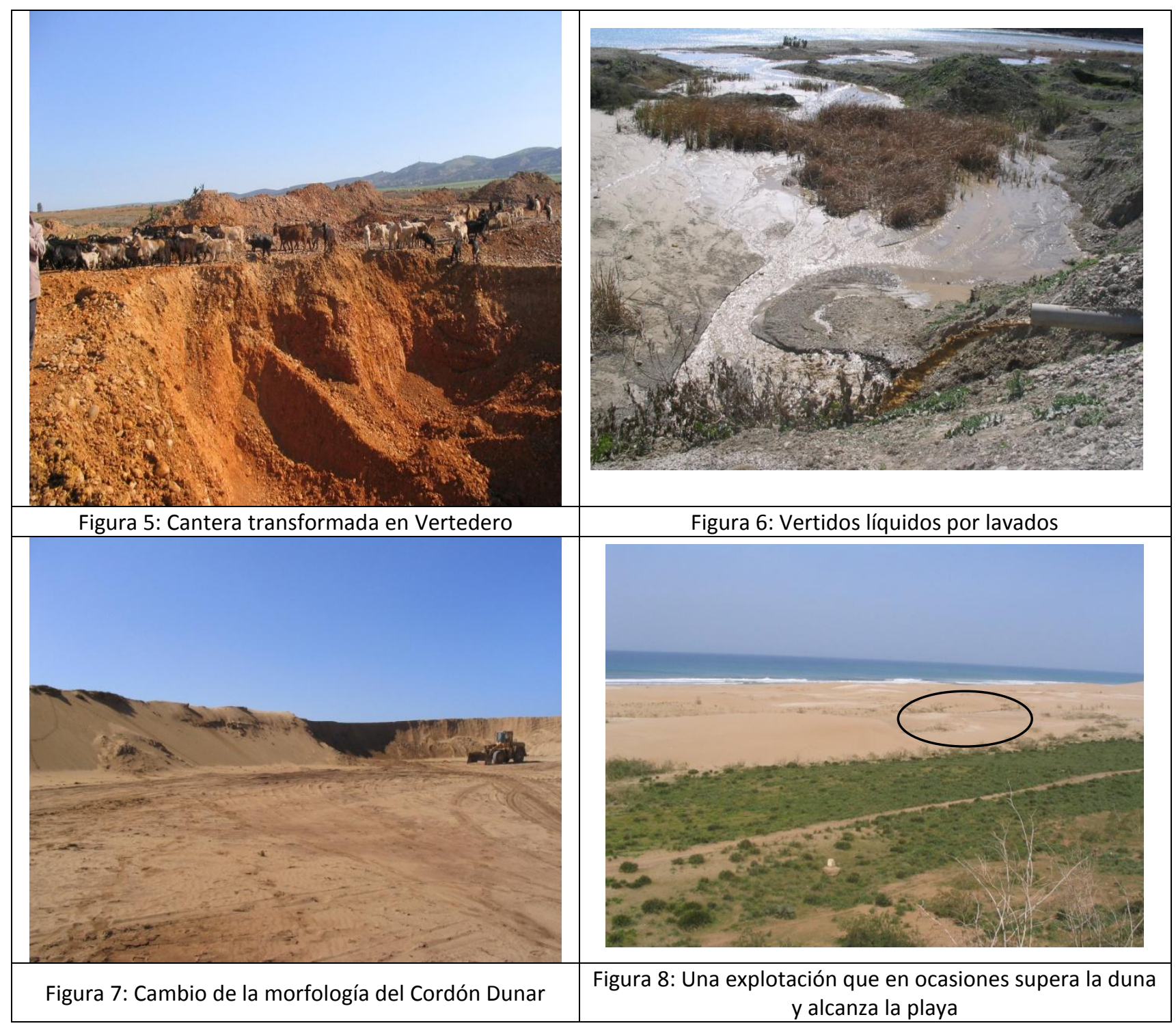

A su vez el transporte de los materiales por las máquinas genera una compactación del suelo.

\section{IDENTIFICACIÓN DE IMPACTOS.}

La concentración de esta actividad extractiva en estas áreas ha causado impactos de los cuales cabe destacar los siguientes:

ISSN: 0212-8594 ISSN-e: 2340-2776. № DOI: http://dx.doi.org/10.12795/rea.2013.i30.01

REA 30 (2013):1-26

http://www.publius.us.es/estudios_andaluces 
-Cambios importantes en la morfología de la playa.

Las investigaciones llevadas a cabo nivel del cordón dunar han mostrado que ha sufrido pérdidas importantes que se evidencian en algunos lugares por una erosión del acantilado y la aparición de pasajes entre las dunas, algunos de ellos visibles desde la carretera. La siguiente imagen ilustra este hecho.

Teniendo en cuenta que comúnmente estas actividades no están debidamente planificadas, un bloqueo de las vías de acceso a las canteras provocado por el avance de las dunas ocurre con bastante frecuencia;

\section{-Retroceso de la línea de costa}

La eextracción de arenas ha provocado en algunas áreas del cordón dunar un cambio de con respecto a la línea de costa, ya sea por su retroceso o por la dispersión de las arenas en las zonas costeras. El ingeniero consultor ha podido observar que se ha producido una migración de arenas hacia áreas internas, notablemente hacia el bosque y tierras agrícolas en lo que respecta a las canteras de Bahara Oulad Ayad. Dada la alta sensibilidad del cordón dunar y de la costa, así como la intensidad del impacto, los daños provocados se consideran graves.

-Procesos de erosión, deposición, y riesgos de inundaciones marinas.La sobreexplotación de ciertas zonas del cordón dunar ha tenido como consecuencia el resurgimiento de aguas subterráneas locales. Este hecho puede dar lugar a una contaminación de aguas subterráneas, a pesar de que sean poco sensibles. El desplazamiento costero (erosión de las dunas, playas y formaciones de nueva costa) es un fenómeno natural, pero la acción humana puede influir sobre estos procesos, provocando una modificación de las características físicas y ecológicas de la costa. Como resultado, los hábitats costeros, fluviales y marinos sufren un deterioro físico y biológico por causa de la explotación no sostenible de recursos (especialmente en cuanto a la extracción de arenas a partir de las dunas se refiere). Los impactos identificados a nivel del cordón dunar solo se han podido observar en zonas con cambios significativos (entre Kenitra y Moulay Bousselham).

De norte a sur, se determinan cuatro sectores:

- Sector 1: Sección del cordón dunar Riah Ezzaouia (localidad de Moulay Bousselham).

Esta sección del cordón evidencia la existencia de algunas zonas de erosión. Los más importantes se encuentran en:

Zona 1: deterioro de aproximadamente 12,5 hectáreas identificada a unos $1300 \mathrm{~m}$ de las canteras Riah Ezzaouia.

ISSN: 0212-8594 ISSN-e: 2340-2776. № DOI: http://dx.doi.org/10.12795/rea.2013.i30.01

REA 30 (2013):1-26

http://www.publius.us.es/estudios_andaluces 
Zona 2: deterioro de aproximadamente 1 hectárea registrada a unos $2 \mathrm{Km}$. de las canteras de Riah Ezzaouia.

Zona 3: deterioro de aproximadamente 5,5 hectáreas localizada a unos 400 metros de las canteras de Riah Ezzaouia. Este caso sin duda se encuentra relacionado con las actividades mineras que se practican en esta área.

Zona 4: deterioro de aproximadamente 7,5 hectáreas que se encuentra en el centro de Moulay Bousselham a unos 3,5 Km. de las canteras de Riah Ezzaouia. Esto sin duda puede vincularse al aumento de la tasa de urbanización a nivel del cordón dunar.

- Sector 2: Sección del cordón dunar "Bahara Oulad Ayad".

Las dunas en esta zona cuentan con una longitud total de aproximadamente $28 \mathrm{Km}$. lineales.

Se observa a lo largo del cordón una degradación progresiva. Las áreas de mayor afectación por la erosión se encuentran al sur y al norte de la duna.

Sabiendo que no se ha detectado ninguna actividad extractiva de importancia en la duna Bhara Oulad Ayad, este cambio solo puede atribuirse a factores naturales y antropogénicos (dinámica fluvial, el cambio climático, el desarrollo local, etc.)

- Sector 3: Sección del cordón dunar "Mansour Ben".

En el mismo informe se puede constatar que el fenómeno erosivo en esta sección permite identificar dos zonas erosionadas de una extensión total de aproximadamente 83 hectáreas. La primera zona se encuentra a unos $5 \mathrm{Km}$. de la cantera de Ben Mansour y la segunda a unos $8 \mathrm{Km}$. de la misma.

- Sector 4 Sección del cordón dunar O. Assal Fzara y Chlihat Oled Berjal (localidad de Mnasra).

En esta parte del cordón dunar, la erosión es poca en comparación con la observada en Bhara Oulad Ayad. Sin embargo algunas áreas erosionadas se identificaron a unos 2,5 Km. al sur de las canteras Chlihat $O$ Berejal y a unos $4 \mathrm{Km}$. al norte de las canteras de Oulad Assal Fzara.

Se estima que la erosión ha afectado alrededor de 93 hectáreas.

Parece que a pesar de la concentración de canteras activas en esta parte del cordón, se han encontrado algunas zonas de ensanchamiento en Chlihat O Berejal.

ISSN: 0212-8594 ISSN-e: 2340-2776. № DOI: http://dx.doi.org/10.12795/rea.2013.i30.01

REA 30 (2013):1-26

http://www.publius.us.es/estudios_andaluces 
Estudiando cada uno de los casos anteriores y a la luz de los resultados obtenidos, los impactos debidos a la extracción de arena en el cordón dunar se relacionan principalmente con los cambios evidenciados en su morfología. Sin embargo, estos impactos son de nivel bajo y/o medio debido a su carácter temporal y su alcance permanece muy ligado al ámbito local.

El bajo nivel de los impactos en Mnasra solo puede explicarse por un aporte continuo en esta zona del cordón. De hecho la existencia de algunas zonas de ensanchamiento identificadas al sur del cordón apoya esta hipótesis.

En cuanto a las áreas no sometidas a extracciones y/o procesos de erosión [Bhara Oulad Ayad, el Sur de Ben Mansour, el Sur y el Norte de Mnasra así como las zonas 1,2 y 4 de Moulay Bousselham], este fenómeno puede estar relacionado con la combinación de factores naturales y antropogénicos, tales como:

- Aumento del nivel del mar.

- La neotectónica.

- Parámetros hidrodinámicos.

- Las actividades humanas.

Otros impactos importantes causados por las canteras de arena a nivel de la región están relacionados con los costes adicionales generados por el deterioro de las infraestructuras viarias (carreteras, puentes, autovías), asociado al importante tráfico de vehículos para el transporte de los conglomerados que se ha registrado en algunas secciones.

Se estiman en aproximadamente 80.000 el número de desplazamientos al año (camiones de 20 toneladas), para el transporte y la entrega de conglomerados principalmente a dos destinos concretos:

- El 70\% desde las canteras de Mnassra por la carretera de Kenitra-Rabat-

- El $30 \%$ desde las canteras Riah Zaouia por la carretera de Moulay-Bousselham Larache, o a través de la RR406, la RP4216 y de la RP4214 y hacia Sidi Slimane, Souk Larbâa y la región de Fez-Meknes.

Se identifican otros impactos negativos, a nivel de las zonas urbanas, relacionados con la contaminación acústica, el tráfico y los accidentes debido al paso de los transportes, sobre todo en horas punta de tráfico o de bajo nivel de ruido (durante la noche, temprano por la mañana).

ISSN: 0212-8594 ISSN-e: 2340-2776. № DOI: http://dx.doi.org/10.12795/rea.2013.i30.01

REA 30 (2013):1-26

http://www.publius.us.es/estudios_andaluces 
El cierre por parte de las autoridades de algunas canteras de arena, incluyendo Benmansour a pesar de que contribuye en la protección del medio ambiente, ha provocado un impacto económico negativo en la economía local, en la mano de obra y ha provocado el desarrollo de una actividad minera anárquica, ejercida por camioneros, cerca del intercambiador de Sidi Allal Tazi.

La precariedad de la extracción de arena desde el norte de la ciudad de Bahara Oulad Ayad a Oulad Mesbah Lakbar (círculo de Sidi Mohamed Lahmar), se puede evidenciar por la aparición de trastornos vinculados al posible agotamiento de recursos y por el afloramiento de agua debido a la baja reserva de arena encontrada permitiendo que se alcance al estrato arcilloso cuando se alcanza una profundidad de 3 a $5 \mathrm{~m}$.

A nivel paisajístico, con la excepción de las canteras de arena de Benmanssour las cuales permanecen a día de hoy sin colmatar por los flujos de arena, el impacto de estas canteras de arena es muy bajo debido a su ubicación frecuentemente refugiados de los principales ejes de circulación por carreteras.

Además de estos impactos negativos, cabe destacar un impacto socio-económico positivo importante que se genera a nivel local por las canteras de arena colectivas: la mano de obra local no cualificada que realiza la carga de camiones (200Dh por carga). Estas canteras ofrecen a la región cerca de 100 empleos directos y 300 empleos indirectos. Esta actividad contribuye a proporcionar empleo a la mano de obra local, y reducir el desempleo mediante la creación de nuevos puestos de trabajo directos e indirectos.

\section{CONCLUSIONES.}

Los impactos asociados a la explotación de canteras en la región de Kenitra se resumen en:

- Cambios en la morfología de algunas secciones del cordón dunar, en particular en aquellas donde el ensanchamiento de la duna es casi nula;

- Una mayor vulnerabilidad de la capa freática de Drader Souier tras las extracciones realizadas en una zona de recarga (Lalla Mimouna);

- Una mayor vulnerabilidad de la capa freática de Maamora debido a la presencia de cavidades excavadas a nivel del medio por el que las aguas se infiltran y circulan rápidamente, sin filtración, con el riesgo de contaminación de las cuencas AEP, principalmente a nivel de Sidi Taibi;

ISSN: 0212-8594 ISSN-e: 2340-2776. № DOI: http://dx.doi.org/10.12795/rea.2013.i30.01

REA 30 (2013):1-26

http://www.publius.us.es/estudios_andaluces 
- Impacto en las infraestructuras viarias vinculadas al tráfico;

- Impacto en la seguridad pública con motivo del tráfico de camiones por las ciudades, la densidad del tráfico, el tipo de vehículos utilizados y los horarios de transporte.

- Impacto a nivel de paisaje en las áreas de concentraciones de canteras, incluidas las situadas en las principales carreteras, las más transitadas (autovías, etc.).

- Impacto sobre la calidad del aire de la calidad de vida de la población causado por las emisiones de polvo, por ruidos y vibraciones;

Basándonos en estas limitaciones ambientales se pueden definir directrices para la gestión de canteras en la zona estudiada. Estos planes de gestión se centrarán en el uso racional de los materiales con el fin de preservar y evitar el agotamiento por un consumo descontrolado de los yacimientos de materiales de alta calidad, sobre todo en cuanto a dunas de arena se refiere, $\mathrm{y}$ al mismo tiempo protegiendo el medio ambiente y el sector socioeconómico.

\section{BIBLIOGRAFÍA.}

Aberkan, M. (1989) : Etude des fOl1Tlations Quaternaires des marges du bassin du Rharb (Maroc Nord-occidental).Bordeaux 1. Thèse. Doc. ès sc. Univ Bordeau I, 290pp.

AHBS (2010) : Ressources en eau dans le Bassin du Sebou.

Bryssine (1992): In Talib, H. (2005): Étude de la vulnérabilité à la pollution de la nappe du Gharb, Evaluation par les méthodes DRASTIC et GOD, Diplôme des Etudes Supérieures Approfondies (DESA) en Hydrogéologie, Université Sidi Mohamed Ben Abdellah, Faculté des Sciences Dhar el Mahraz Fès, Département de Géologie.

Combe, M, (1967) In Talib, H. (2005): Étude de la vulnérabilité à la pollution de la nappe du Gharb, Evaluation par les méthodes DRASTIC et GOD, Diplôme des Etudes Supérieures Approfondies (DESA) en Hydrogéologie, Université Sidi Mohamed Ben Abdellah, Faculté des Sciences Dhar el Mahraz Fès, Département de Géologie.

Combe, M. et al. (1975) : Le bassin des oueds Drader et Soueir. in Ressources en Eau du Maroc, Tome 11, Plaines et Bassins du Maroc Atlantique, Ministère des Travaux Publics et

ISSN: 0212-8594 ISSN-e: 2340-2776. № DOI: http://dx.doi.org/10.12795/rea.2013.i30.01

REA 30 (2013):1-26

http://www.publius.us.es/estudios_andaluces 
des Communications. Direction de I'Hydraulique. connaissances actuelles. Trav. Inst. Sci. Rabat. ser. Zool. 38: 1-147.

El Gharbaoui, A. (1987): Les climats : Géographie physique et géologie. Grande eNcyclopédie du Maroc, Volume 3, pp.14-31.

Kacimi, Ilias (1992): Quelques aspects sur I'hydrogéologie et I'hydrochimie des nappes aquifères du Gharb-Maroc. Le problème particulier du fer et du manganèse. 154 p.

Michard, A. (1976): Elément de géologie marocaine. Rabat, ot.et Mém. Sery. Géol. Maroc, n0252, 422 pp., 221 fig., 8 tabl., 6 pl.-phot.

OMVAG (Office Régional de Mise en Valeur Agricole du Gharb) : Date non indiquée: Monographie de l’Office Régional de Mise en Valeur Agricole du Gharb, Rapport préliminaire.

\section{Direcciones Web:}

http://www.ormvag.ma/ (14/03/2012)

http://www.abhsebou.ma/(12/03/2012)

http://sites.google.com/site/collectivitesaumaroc/regions/gharbchrardabeni-hssen $(16 / 03 / 2012)$ 